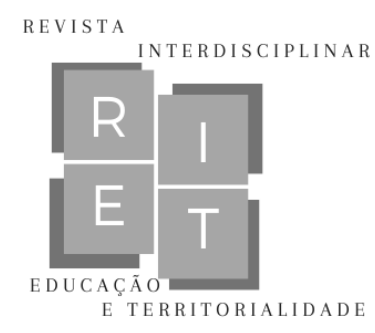

\title{
Educação em contexto de pandemia: breves reflexões
}

\author{
Education in pandemic context: brief reflections
}

\section{Educación en el contexto de una pandemia: breves reflexiones}

\begin{abstract}
Mônica Mendes da Cunha Pestana
Programa de Pós-Graduação em Educação, Universidade Federal de Mato Grosso do Sul (UFMS) Corumbá, Mato Grosso do Sul, Brasil.

E-mail: mendescunha1@ hotmail.com

ORCID: https://orcid.org/0000-0001-8782-7593

Mônica de Carvalho Magalhães Kassar

Programa de Pós-graduação em Educação, Universidade Federal de Mato Grosso do Sul (UFMS)

Corumbá, Mato Grosso do Sul, Brasil.

E-mail: monicakkassar@gmail.com

ORCID: https://orcid.org/0000-0001-5577-6269
\end{abstract}

\begin{abstract}
Resumo: Desde o início de 2020, as escolas brasileiras foram fechadas, seguindo as recomendações internacionais para controle da disseminação da pandemia de Covid-19. Diante dessa, as escolas tiveram que se adaptar à situação rapidamente. Considerando esse contexto, os propósitos deste artigo são apresentar reflexões iniciais sobre as maneiras como o isolamento social tem contingenciado os processos de escolarização no Brasil e evidenciar desafios a serem enfrentados. O presente estudo caracteriza-se como um trabalho exploratório sobre a temática, a partir de busca de material bibliográfico e documental disponível na internet. Verificou-se que documentos divulgados pelo Ministério da Educação são superficiais no que se referem-se às formas de enfrentamento aos desafios cotidianos da escola básica, especialmente à falta de infraestrutura escolar e às características precárias de vida de parte significativa da população brasileira. O material bibliográfico localizado indica a existência de considerável quantidade de publicações sobre o tema no Brasil e o registro de desafios de diversas ordens às escolas, especialmente aos docentes, que têm sido tomados como atores fundamentais nesse contexto.
\end{abstract}

Palavras-chave: Pandemia. Covid-19. Educação. Educação Escolar. Educação básica

Abstract: Since the beginning of 2020, Brazilian schools have been closed, following international recommendations for controlling the spread of the Covid-19 pandemic. Faced with this, schools had to adapt to the situation quickly. Considering this context, the purposes of this article are to present initial reflections on the ways in which social isolation has affected schooling processes in Brazil and to highlight challenges to be faced. The present study is characterized as an exploratory work on the theme, based on the search for bibliographic and documentary material available on the internet. It was found that documents released by the Ministry of Education are superficial about ways of coping with the daily challenges of the basic school, especially the lack of school infrastructure and the precarious life characteristics of a significant part of the Brazilian population. The 


\section{Educação em contexto de pandemia: breves reflexões}

bibliographic material found indicates the existence of a considerable number of publications on this issue in Brazil and the registration of challenges of different orders to schools, especially for teachers, who have been taken as fundamental actors in this context. Keywords: Pandemic. Covid-19. Education. Special Education. School Education. Basic education

Resumen: Desde principios del 2020, las escuelas brasileñas han estado cerradas, siguiendo las recomendaciones internacionales para controlar la propagación de la pandemia de Covid19. Ante esto, las escuelas tuvieron que adaptarse rápidamente a la situación. En este contexto, los propósitos de este artículo son presentar reflexiones iniciales sobre las formas en que el aislamiento social ha afectado los procesos de escolarización en Brasil y destacar los desafíos a enfrentar. El presente estudio se caracteriza por ser un trabajo exploratorio sobre el tema, basado en la búsqueda de material bibliográfico y documental disponible en Internet. Se encontró que los documentos difundidos por el Ministerio de Educación son superficiales en cuanto a las formas de afrontar los desafíos cotidianos de la escuela básica, especialmente respecto a la falta de infraestructura escolar y las precarias características de vida de una parte importante de la población brasileña. El material bibliográfico encontrado indica la existencia de un número considerable de publicaciones sobre el tema en Brasil y el registro de desafíos de diferentes órdenes a las escuelas, especialmente a los docentes, quienes han sido tomados como actores fundamentales en este contexto.

Palabras llave: Pandemia. Covid-19. Educación. Educación Especial. Enseñanza escolar. Educación básica.

Data de recebimento: 19/04/2021

Data de aprovação: 10/06/2021

DOI: $10.30612 /$ riet.v\%vi\%i.14561

\section{Introdução}

Ao explorar a página WEB do Ministério da Educação é possível encontrar um grande ícone denominado "Coronavírus - ações do MEC em resposta à pandemia de COVID-19"1. Ali, há um relatório de atividades do Comitê Operativo de Emergência (COE) do ministério, que compreende março/2020 a março/2021, com ações para educação básica, ensino superior, educação profissional e tecnológica. A existência desse documento indica que a situação atual das instituições educacionais brasileiras não é usual, mas está em grande parte impactada pelas medidas de isolamento social.

O documento (BRASIL, 2021) informa que a pandemia afetou diretamente a educação escolar básica, com a suspensão das aulas presenciais em todas as redes de ensino, situação que perdura até o presente momento, em diversas regiões do país. Esse contexto solicita a proposição de alternativas para a continuidade do processo educativo, ou, segundo

\footnotetext{
${ }^{1}$ Disponível em https://www.gov.br/mec/pt-br/coronavirus
} 


\section{Educação em contexto de pandemia: breves reflexões}

o documento, demanda "políticas e medidas educacionais inovadoras e eficientes para garantir o mínimo de impacto no ensino e na aprendizagem escolar” (p. 6).

Essas medidas dizem respeito a tentativas de enfrentamento a uma doença causada por um tipo de coronavírus, o SARS-CoV-2. Em dezembro de 2019 foram constatados os primeiros rumores de uma doença respiratória, com sintomas e níveis de propagação similares de uma gripe, na cidade de Wuhan, China. Apesar de símile ao resfriado, nos casos agravados mostrava uma Síndrome Respiratória Aguda Grave (SRAG), e, após crises de deficiência respiratórias, poderia levar a óbito. Em 11 de março de 2020, a Organização Mundial da Saúde (OMS) declara estado de emergência, diante de um número crescente de suspeitas e confirmações dessa doença em diferentes partes do mundo, concluindo que se tratava, de fato, de uma pandemia. Como uma das medidas de enfrentamento à situação foi adotado o isolamento social, com o intuito de diminuição da propagação do vírus. Tal medida afetou diferentes campos da vida em sociedade e, de modo especial, as instituições escolares. Até o momento, como observam Araújo e Oliveira, Gomes e Barcellos, (2020, p. 558), permanecem incertos a ocorrência, a magnitude das perdas e os efeitos sobre diferentes grupos de alunos.

Diante desse cenário de muitas indagações e perguntas - muitas ainda sem respostas -, o presente artigo tem como objetivos apresentar reflexões iniciais sobre as maneiras como o isolamento social tem contingenciado os processos de escolarização no Brasil e evidenciar desafios a serem enfrentados. Para o desenvolvimento deste trabalho, foi realizada uma investigação bibliográfica e documental, de caráter exploratório. Para o levantamento documental, foram consultadas páginas WEB do Governo Federal, especialmente as ligadas ao Ministério da Educação, Ministério da Saúde e ao SUS. No estudo bibliográfico, a delimitação geográfica do material consultado é o Brasil. Foram buscados artigos, em língua portuguesa, disponíveis na Plataforma Scielo e no Google Acadêmico, a partir da combinação dos descritores "COVID 19" e "Educação", "COVID 19" e "Educação Especial", "Pandemia" e "Educação" e "Pandemia" e "Educação Especial". Em todos os casos, foram privilegiados os artigos que tratam da Educação Básica no Brasil. Para análise do material, buscamos identificar temas recorrentes, a partir do diálogo com pesquisas recentes pertinentes à temática.

\section{COVID-19 e o cenário atual brasileiro}




\section{Educação em contexto de pandemia: breves reflexões}

Segundo orientações emanadas pelo Ministério da Saúde brasileiro², os coronavírus são uma grande família de vírus comuns em muitas espécies diferentes de animais. Raramente, esse vírus, comuns em outras espécies, poderia infectar as pessoas. O novo integrante dessa família, SARS-CoV-2, passou a infectar humanos e recebeu o nome de Covid-19 decorrente da combinação entre a palavra COrona VIrus Disease (Doença do Coronavírus), enquanto o número 19 se refere ao ano da sua propagação. ${ }^{3}$

Quando apontamos a pandemia do coronavírus como um cenário atípico, não queremos dizer que o mundo nunca tenha vivido um momento pandêmico antes. Pelo contrário, o mundo já viveu diferentes tipos de pandemias e, como aponta Grisotti (2010), decorrente de inúmeros fatores, as possibilidades da Covid-19 ser a última são baixas.

As consequências, para a saúde humana, da versatilidade dos vírus e das bactérias e da dificuldade na produção instantânea de medicamentos, aliadas ao uso indiscriminado de antibióticos e à falta de preocupação com saneamento básico e, de certa forma, com a medicina preventiva, evidenciam a problemática já trabalhada, em épocas anteriores, pelos epidemiologistas e, atualmente, pelas várias abordagens dos riscos (GRISOTTI, 2010, [s.p.]).

Em um contexto histórico e social totalmente diferente do existente hoje, em 1918, após a Primeira Guerra Mundial, soldados passaram a ser vitimados por uma doença de origem desconhecida. Se tratava da Gripe Espanhola ${ }^{4}$ e, conforme afirma Bertucci-Martins (2003), o número de mortes foi muito grande em pouco tempo. Apesar da imprecisão dos registros, pesquisas apontam (BERTUCCI-MARTINS, 2005; SANTOS, 2006; SOUZA, 2005 apud KIND; CORDEIRO, 2020) que a influenza tenha feito cerca de 20 milhões de vítimas no mundo todo, mais que os quatros anos da Primeira Guerra Mundial, que vitimou em torno de 8 milhões de pessoas.

As primeiras notícias chegadas ao Brasil sobre a Gripe foram subestimadas pelas autoridades locais, sob uma abordagem de pseudocientificidade, como analisado por Goulart (2005) nos estudos de Kind e Cordeiro (2020). "De forma geral, os textos apontam que os

\footnotetext{
2 Disponível em: https://www.gov.br/saude/pt-br/coronavirus/perguntas-e-respostas/covid-19/o-que-e-ocoronavirus

3 Informações retiradas do site oficial do Ministério da Saúde. Disponível em: https://coronavirus.saude.gov.br/sobre-a-

doenca\#: :text=A\%20COVID\%2D19\%20\%C3\%A9\%20uma,infec\%C3\%A7\%C3\%B5es\%20assintom\%C3

$\%$ A1ticas\%20a\%20quadros\%20graves. Acesso em: 15 mar. 2020.

${ }^{4}$ Segundo Kind e Cordeiro (2020) a Gripe Espanhola recebeu este nome porque foram os jornais da Espanha, país neutro na guerra, que começou a divulgar o surto que estava vitimando os combatentes.
} 


\title{
Educação em contexto de pandemia: breves reflexões
}

governantes no Brasil minimizaram a doença, propalando que era apenas uma gripe comum, passageira e benigna (KIND, CORDEIRO, 2020, [s.p.].)”. A citação refere-se à pandemia ocorrida em 1918, apesar de símile ao cenário atual.

\begin{abstract}
Apesar dos esforços [...] de pesquisadores da época, havia desconhecimento sobre a doença[...]. A falta de conhecimento da medicina e da ciência sobre o contágio, diagnóstico e tratamento e a lentidão dos governos em darem respostas satisfatórias fizeram com que as pessoas se sentissem entregues à própria sorte. [...] Numa época em que não existia rádio e nem televisão, o jornal impresso era o principal veículo de comunicação, fórum privilegiado de discussão pública sobre a "espanhola". Os jornais registravam as cenas do cotidiano alterados pela pandemia, traziam estatísticas sobre os contaminados e mortos, apresentavam o debate da comunidade médica e das diferentes forças políticas. Também veiculavam as prescrições sanitárias governamentais e as práticas adotadas pela população para conter a doença. Apesar da importância da imprensa nesse período, $65 \%$ da população era analfabeta $\mathrm{e}$, provavelmente, não tomava conhecimento do debate político sobre a "espanhola" veiculado nos jornais. Outro dado do contexto a ser considerado é que era uma sociedade que tinha abolido a escravidão muito recentemente e tinha relegado milhares de homens e mulheres negros à própria sorte, sem nenhum amparo econômico, social e político do Estado (KIND, CORDEIRO, 2020, [s.p.]).
\end{abstract}

Couto, Couto e Cruz (2020, p. 202-203) advertem que "A primeira reação é quase sempre de perplexidade diante de um mal que avança sem controle [...]. Isso, muitas vezes, explica a demora das autoridades públicas para adotar medidas sanitárias. Em todas as epidemias, $[. .$.$] vence-se essa inércia inicial".$

Passados pouco mais de cem anos desde a Gripe Espanhola, numa similar atmosfera de total despreparo por parte do governo federal, o país foi surpreendido no ano de 2020. Entre o período de dezembro de 2019 a fevereiro de 2020 e com uma distância de $17.471,88$ km do Brasil, Wuhan, na China, parecia estar em um momento delicado, permeando uma grande crise sanitária, mas "longe" do Brasil. Diante de tamanha distância, de início, as especulações eram de que o problema passaria. Enquanto isso, do lado de cá, as redes sociais eram bombardeadas por mídias digitais sem comprovações fatídicas que causavam pânico e, até então, cautela diante de uma possível propagação. Neto et al. (2020) estudam a disseminação das informações falsas sobre a pandemia no Brasil e explicam:

Muitas informações e notícias foram postadas nas mídias sociais, o que conduziu a diversos compartilhamentos, criando uma rede com conteúdo e pseudoinformações, conhecidas como Fake News. Em tempos de avanços tecnológicos, estas notícias falsas são veiculadas nas redes sociais, de 


\section{Educação em contexto de pandemia: breves reflexões}

forma rápida e multiplicada entre a população, que, em linguagem metafórica, pode-se entender como um vírus que contamina a comunicação e promove ações e comportamentos contrários às orientações das autoridades técnicas no campo da saúde. (s/p).

O mês de fevereiro se inicia com a realização de uma missão de repatriamento de brasileiros que viviam na cidade de Wuhan. Além dos 34 brasileiros repatriados, outros 24 estavam envolvidos na operação, nomeada Operação Regresso, iniciando assim, entre esses brasileiros, a quarentena no país. Com o período de isolamento procedido com sucesso, ocorreu a liberação dessas pessoas, fazendo com que, até aquele momento, o Brasil permanecesse aparentemente distante do problema. No entanto, a lista de países com casos suspeitos cresceu, deixando o mundo em alerta e, no Brasil, o final do Carnaval de 2020 foi marcado com o primeiro caso confirmado de coronavírus, na cidade de São Paulo, dando início ao período caótico que pressiona o Sistema Único de Saúde. ${ }^{5}$

No início de março de 2020, o diretor geral da Organização Mundial de Saúde (OMS) declarou a elevação do estado da contaminação à pandemia de Covid-19, devido à rápida disseminação geográfica apresentada ${ }^{6}$.

Atualmente, o Brasil acumula novos casos e coleciona óbitos decorrentes das consequências de agravamento da doença causada pelo vírus, conforme podemos observar na tabela abaixo.

Tabela 1 - Síntese de casos, óbitos, incidência e mortalidade.

\begin{tabular}{lcccc}
\hline Região & Casos & Óbitos & Incidência/100 mil hab. & Mortalidade/100mil hab. \\
\hline Brasil & 12.573 .615 & 313.866 & 5983,2 & 149,4 \\
\hline Centro-Oeste & 1.333 .297 & 28.528 & 8181,2 & 175,0 \\
\hline Sul & 2.469 .847 & 45.904 & 8239,4 & 153,1 \\
\hline Norte & 1.336 .951 & 32.156 & 7253,8 & 174,5 \\
\hline Nordeste & 2.887 .370 & 67.717 & 5059,2 & 118,7 \\
\hline Sudeste & 4.546 .150 & 139.561 & 5144,4 & 157,9 \\
\hline
\end{tabular}

Fonte: Secretaria Estaduais de Saúde. Brasil, 2021. Dados atualizados em 29 mar. 2021 às 18h40m. Disponível em: <https://covid.saude.gov.br/>

Os dados apontam números resultantes de uma caminhada de pouco mais de um ano de convivência entre a população brasileira e a COVID-19.

\section{Educação versus pandemia ou educação na pandemia?}

\footnotetext{
5 Informações retiradas do site oficial do Ministério da Saúde. Disponível em: <https://coronavirus.saude.gov.br/linha-do-tempo/\#fev2020> Acesso em: 12 mar. 2020.

6 Disponível em https://www.unasus.gov.br/noticia/organizacao-mundial-de-saude-declara-pandemia-decoronavirus
} 


\section{Educação em contexto de pandemia: breves reflexões}

Em 2020, iniciávamos o ano letivo em todas as escolas do país e com poucas semanas do início das atividades fez-se necessária a interrupção das aulas em instituições públicas e privadas. Esse fato surpreendeu professores(as), profissionais atuantes em todas as áreas das escolas, pais e responsáveis, e, sobretudo, os estudantes. Acionando coletivos questionamentos, como: E de agora em diante como será? Quanto tempo isso irá durar? E, de modo angustiante, com o passar dos dias essas e outras inúmeras perguntas não foram sanadas.

De forma abrupta, mas natural em uma situação de crise, de alerta mundial, as aulas foram interrompidas. Os professores e professoras não retornaram às escolas para buscar o material que já haviam preparado para aquele início de ano letivo. Os armários ficaram sendo os guardiões de planejamentos e propostas pedagógicas. (MONTEIRO, 2020, p. 239).

Guizzo, Marcello e Müller (2020) argumentam que o isolamento social acionou "práticas, ações, atitudes que colocam em cena tanto a manutenção (de desigualdades, de hierarquias, de formas de controle), como a criação de formas de existir; tanto o fortalecimento (dessas mesmas desigualdades, hierarquias e formas de controle), como sua suspensão" (p. 3). Algumas dessas mudanças e manutenções estão presentes na literatura que se propõe analisar a situação da escola brasileira nesse contexto.

Claitonei Santos (2020) aponta o período de pandemia como uma pane dentro da categoria dos profissionais da educação, em especial, da categoria docente. Isso decorrente da necessidade de uma relação de interação constante com os educandos, principal ponto que a pandemia retirou. $\mathrm{Na}$ impossibilidade do contato presencial, entrou em cena o ambiente do contato remoto para a realização das atividades acadêmicas, decisão esta que não passou - necessariamente - pelos professores:

Ao cabo de mais alguns dias algumas outras notícias começaram a ganhar o cenário: as aulas seriam "dadas", de forma remota, usando do ensino a distância, também para os estudantes da Educação Básica, dentre eles os alunos e alunas da Educação Infantil e Ensino Fundamental. Começam as inúmeras "idas e vindas", "disse que não disse" infelizmente, corriqueiros no cenário brasileiro atual não apenas na área da educação. Em meio a tudo isso, os menos consultados, ouvidos ou considerados: professores, professoras, estudantes e suas famílias (MONTEIRO, 2020, p. 239).

A prática pedagógica, que por si só já abrange particularidades e enormes responsabilidades, com o passar dos dias e o agravamento da situação, trouxe múltiplos 


\section{Educação em contexto de pandemia: breves reflexões}

desafios. Dentre as responsabilidades de ensinar o conteúdo escolar, acrescentaram-se outras pelejas. Do cenário das salas de aulas lotadas com diferentes perfis e personalidades de alunos agora era necessário compreender as especificidades desses alunos por meio de uma tela de computador/celular.

Além disso, a pandemia trouxe uma acirrada disputa entre a concentração e a desatenção, dentro de um cenário domiciliar totalmente diferente de uma sala de aula. Uns no quarto, com mesa e computador, outros na cama com o celular do responsável, alguns no quintal junto à trilha sonora de qualquer ambiente urbano, e muitos ausentes, sem a possibilidade de acesso, conjunturas que aumentam a distância entre oportunidades, possibilidades e impossibilidades dos diferentes grupos sociais, como Avelino e Mendes (2020) advertem:

A falta de recursos tecnológicos destinados à educação acaba por inviabilizar ainda mais o acesso à educação durante a pandemia, se antes a dificuldade estava em chegar até as escolas, agora muitos alunos vão enfrentar o fato de não terem recursos suficientemente para acompanhar as aulas online e executar as atividades solicitadas (p. 58).

A carência de recursos tecnológicos faz parte de um contexto amplo de desigualdades econômicas e sociais que marcam a história do Brasil e adentram as escolas, como denuncia Veiga Neto (2020): “a educação escolar, em nosso país, acumula uma secular tradição de desigualdades estruturais, exclusões de toda ordem, elitismo descarado, facilitação, aligeiramento e superficialidade curricular" (p. 11).

Dentre as muitas exclusões, soma-se o fato de que mais 46 milhões $^{7}$ de pessoas no país não acessam a rede, apesar de crescimento percentual de brasileiros com acesso à internet nas últimas décadas.

A impossibilidade de acesso à internet é mais frequente em regiões distantes dos centros urbanos. Como registraram Nozu e Kassar (2020), em pesquisa com escolas nas regiões ribeirinhas do Pantanal Sul-mato-grossense, nessas localidades, "os desafios são potencializados e ampliados, exigindo da gestão, dos professores, dos alunos e das famílias alternativas diferenciadas em relação às instituições de ensino dos centros urbanos" (p. 3), para manter as atividades escolares em funcionamento na pandemia.

\footnotetext{
${ }^{7}$ Dados divulgados pelo Instituto Brasileiro de Geografia e Estatística (IBGE), acessados pelo site oficial do Agência Brasil. Disponível em: <https://agenciabrasil.ebc.com.br/economia/noticia/2020-04/um-em-cadaquatro-brasileiros-nao-tem-acesso-internet> Acesso em: 13 mar. 2021.
} 


\section{Educação em contexto de pandemia: breves reflexões}

Mesmo dentre os que têm acesso à rede, há as fragilidades dos serviços de internet em todo o país, que frequentemente entram em manutenção e causam interrupção abrupta, sem qualquer aviso prévio. Como exemplo, temos as cidades de Corumbá e Ladário, isoladas no meio do Pantanal do estado de Mato Grosso do Sul, que frequentemente sofrem com a interrupção dos serviços de banda largada prestados por uma empresa privada de telefonia. Uma matéria jornalística local recente denuncia que a "situação parece não ter solução, pois todos os dias a internet banda larga "vai e volta" e muitas vezes, fica interrompida por horas [...]" (Diário Corumbaense, 2021).

Ressalta-se que a existência de acesso à internet e a presença de recursos de Tecnologia de Informação e Comunicação nas escolas não são garantias de situações adequadas nesses aspectos. Estudo avaliativo realizado no Rio de Janeiro e publicado em 2011, de Sorj e Lissovsky (2011), já alertava para o fato de que, nas análises empreendidas, todos quesitos necessários para um bom funcionamento do sistema em escolas apresentavam insuficiências significativas.

A despeito das dificuldades, o Ministério da Educação entende que "a adoção de atividades de ensino remoto representa um meio de resguardar o processo de aprendizagem e de manter vivo o vínculo do estudante com a instituição" (BRASIL, 2021, p. 45). Para Claitonei Santos (2020), o novo método de ensino veiculado pelas Live, Webinar etc. é ultraotimista e apressado por dois motivos. O primeiro por se apresentar como uma resultante de desfecho para o futuro da educação, ou, em suas próprias palavras, "um vir a ser que não se tem como saber como será". E o segundo se deve ao fato de que essa perspectiva não pode ser sustentada do ponto de vista teórico, e, assim como afirmado pelo autor "não se pode olhar para o futuro sem refletir o presente e também analisar o passado e as ações nele desenvolvidas" (SANTOS, C.,2020, p. 45).

Gatti (2020, p. 32) lembra que no contexto do ensino remoto, diferentes caminhos "foram encontrados com a utilização de diversas plataformas educacionais, com utilização da internet, solução que se mostrou, na situação, acessível a muitas redes, escolas e seus estudantes, mas não para todos”.

Diante dos limites existentes para o desenvolvimento de atividades digitais, algumas escolas organizam-se, também, com confecção de material impresso que é distribuído aos pais de alunos (NETA; NASCIMENTO; FALCÃO, 2020; NOZU; KASSAR, 2020). 


\section{Educação em contexto de pandemia: breves reflexões}

Independente da forma como o ensino remoto tem ocorrido, o ponto vultoso desse contexto de pandemia deve ser observado na enorme responsabilidade atribuída ao docente. Como registram Saraiva, Traversini e Lockmann (2020), em estudo no Rio Grande do Sul, as escolas têm sido levadas a "inventar estratégias que consigam transferir seu funcionamento para dentro da casa de estudantes e professores" (p. 17), o que não tem sido uma tarefa fácil. Neta, Nascimento e Falcão (2020) afirmam que "Conciliar o isolamento social, a vida privada e o trabalho docente no mesmo espaço e tempo causa aos professores sobrecarga mental, emocional e física" (p. 27) e, apresentando dados de levantamento realizado pelo Departamento de Assuntos Educacionais da Fundação Carlos Chagas, informam ainda que para $65 \%$ de docentes pesquisados, o trabalho pedagógico mudou e ampliou-se após o início das atividades remotas.

Com as alterações decorrentes do ensino remoto, quase que exclusivamente ao docente foi depositada a expectativa de "uma revolução" na educação escolar dentro de um cenário de pós-pandemia - ainda que não tenhamos chegado ao final dela. Claitonei Santos (2020) chama a atenção para o ponto de acreditarmos que ocorreu algum tipo de modernização ou reconstrução do modelo escolar somente pelo fato do professor estar utilizando, agora mais do que nunca, ferramentas tecnológicas.

$\mathrm{O}$ fato de se utilizar as ferramentas e a potencialidade da internet em tempos de globalização não significa novas formas ou práticas pedagógicas de ensino. Tanto que as enormes listas de exercícios para que os alunos resolvam sozinhos em casa têm imperado nos processos de ensino aprendizagem. Não se estabeleceu novas formas de ensino que impulsione a criatividade dos alunos e muito menos uma educação que valorize a reflexão em detrimento de práticas positivistas de ensino e as avaliações tradicionais estão aí para comprovar a manutenção das ações coercitivas das gerações mais velhas sobre as mais novas [...] [É] precipitado e incoerente pensar uma revolução na educação pós- pandemia somente pela boa vontade, disposição e ação do professor que em tempos de isolamento social passou a utilizar mais fortemente os recursos da internet. (SANTOS. 2020, p. 45).

O autor, como já ressaltado por Avelino e Mendes (2020) e Veiga-Neto (2020), também chama a atenção à extrema desigualdade que marca a sociedade brasileira e sua escola, situação agravada no contexto pandêmico:

É preciso pensar as ações em âmbito das políticas públicas para a educação e no seu interior, refletir sobre aquelas que estão voltadas para a formação de professores. Não existe revolução na educação sem a ruptura com o 


\section{Educação em contexto de pandemia: breves reflexões}

elitismo educacional, sem a redução das desigualdades sociais e, consequentemente do darwinismo social, no qual somente os mais fortes e capazes sobrevivem. É preciso pensar a partir da totalidade, não desconsiderar a realidade do aluno, o meio social em que vive e nas condições deste realmente poder aprender, centrar nas necessidades do aluno do século XXI, pensando no tipo de sociedade que se queira formar. (p. 45).

O fechamento das escolas, no atual contexto, e os aspectos acima levam-nos a indagar sobre a garantia de escolarização, com qualidade, para a classe trabalhadora. Silva et al. (2020) alertam que

Tal medida intensificou as discussões, contrárias e favoráveis, sobre o uso do ensino remoto ou $\mathrm{EaD}$, colocando no debate sua pertinência e sua abrangência, expondo fragilidades de acesso aos recursos tecnológicos e de infraestrutura pelas camadas mais pauperizadas da classe trabalhadora (p. 12).

Ainda em relação ao contexto remoto, Carvalho (2020) chama a atenção a um aspecto que nem sempre é considerado nos trabalhos que elaboram reflexões sobre possíveis impactos do fechamento das escolas no período pandêmico. $\mathrm{O}$ autor nos lembra que

as transformações no que concerne à dimensão da presencialidade na experiência escolar não se limitam ao seu aspecto espacial. Elas também se fazem sentir em um âmbito que condensa o próprio sentido do processo educativo: o vínculo temporal que se tece entre as gerações. (p. 6).

Pois, educar também implica "transmitir às novas gerações experiências simbólicas que nos chegam dos vastos domínios do passado e que são apresentadas e ressignificadas, criando as bases para sua durabilidade e renovação no futuro" (p. 6).

Todas essas mudanças levam, dentre outras, às questões relacionadas à formação docente para o enfrentamento da situação. Monteiro (2020) apresenta uma pesquisa com o intuito de pensar sobre a reconstrução e (re)invenção da profissão e da educação escolar em meio à adversidade dos dias atuais. Assinala em seus estudos as Notas de Esclarecimentos/Orientações ( $\left.n^{\circ} 01 / 2020\right)$ e Portarias $\left(n^{\circ} 343\right)$, respaldados pela atual Lei de Diretrizes e Bases da Educação Brasileira (LDB), sobre o uso do ensino a distância e adverte sobre a existência de problemas já levantados por outros autores e em interlocução com Knop (2017):

[...] essa proposta de ensino a distância na Educação Básica tem muito mais 


\section{Educação em contexto de pandemia: breves reflexões}

perguntas que respostas. Perguntas que nascem de questões que não são de simples resolução. Pesquisa realizada pelo Centro Regional de Estudos para o Desenvolvimento da Sociedade da Informação (Cetic.br), em 2018, aponta que 33\% dos domicílios pesquisados não têm acesso a internet (CETIC.BR, 2018). Fato que vem sendo reafirmado pela preocupação expressa por professores e professoras que declaram não ter acesso a internet com velocidade adequada ao planejamento e implementação de um ensino a distância; e por famílias que não têm condições, especialmente financeiras, para oferecer a seus filhos computador a internet em casa. Considerar a oferta de educação nessas condições pode acentuar ainda mais as desigualdades sociais. (KNOP, 2017 apud MONTEIRO, 2020, p. 244).

A autora acrescenta ainda que não é suficiente obter os recursos tecnológicos, mas também é imprescindível saber utilizar esses meios como apoio ao estudo e aprendizagem. A atenção à formação continuada remete à ideia de reinvenção docente:

(Re)inventar a profissão docente em tempos de adversidade não é nada fácil, (re)inventar a nós mesmos e nossos modos de vida em situação de distanciamento social, também não é nada fácil, mas sim, é possível. O convite para nos (re)inventarmos enquanto professores e professoras não é novidade. Ele já vem sendo feito há tempos. Talvez com outros nomes, mas sua natureza de (re)invenção permanece. (MONTEIRO, 2020, p. 249250).

A necessidade de reinvenção parece ser um tópico constante no campo da educação no atual contexto, no entanto, entre escolas públicas e privadas podem ser verificadas práticas construídas de formas muito diferentes, como analisam Guizzo, Marlello e Müller (2020, p. 6), pois “ainda que as redes e as escolas públicas tenham feito esforços de se reinventar em tempos de pandemia, há dificuldades para garantir que todos os estudantes continuem o ano letivo de modo uniforme." (grifo das autoras)

$\mathrm{O}$ ato revolucionário de transformar a educação é repleto de movimentos de altos e baixos, e está incluso dentro uma estrutura social repleta de interesses entrelaçados por relações de poderes, logo não podemos transferir tamanha responsabilidade somente para o educador dentro da sala de aula, com ou sem apoio das mídias sociais. Assim, é necessário ter em mente a definição de educação que estamos buscando alcançar e a dimensão da luta que estamos a desencadear. Isso implica diferentes aspectos dentro do ambiente de ensino, levando-se em conta a realidade dos nossos alunos, o meio social, as condições de cada um e as especificidades.

Dentre as especificidades na escola, há o grupo dos alunos público-alvo da educação especial, que, mesmo dentro de uma proposta de educação inclusiva, recebem olhares 


\section{Educação em contexto de pandemia: breves reflexões}

contraditórios, sendo identificados como os "incluídos". Reflexões elaboradas por Silva, Bins e Rozek (2020), em interlocução com Boaventura Souza Santos (2020), sobre as invisibilidades presentes na sociedade, nos auxiliam a pensar nesses alunos, especialmente no contexto pandêmico. Dentre as "lições" da pandemia, é possível dizer que essa população já vivia, de certo modo, um contexto de isolamento social, decorrente de inúmeras circunstâncias de exclusão explícitas ou não.

Nesse isolamento, o atendimento educacional especializado apresenta-se como um grande desafio. Ozório et al (2021) apontam que a busca por uma educação inclusiva em período anterior à pandemia já se conduzia como a periferia das políticas educacionais, e, diante da atual atmosfera de distanciamento social, se situa ainda mais longe das preocupações governamentais. Assim, ainda que Conselho Nacional de Educação/Ministério da Educação (CNE/MEC), tenha estabelecido diretrizes para a educação especial durante a pandemia, chamando a atenção para o fato de que as atividades pedagógicas não presenciais devem incluir os estudantes com deficiência, transtorno de espectro autista e altas habilidades/superdotação (BRASIL, 2020), a responsabilidade de criar condições para que isso ocorra tem recaído, uma vez mais, sobre os docentes, que lidam com carências estruturais das escolas, além de, nem sempre, possuírem formação adequada (OZÓRIO et $a l$, 2021). Os autores, assim como Ferreira, Januário e Moreira (2021), em pesquisa realizada sobrea situação no Paraná, ressaltam que, a situação de distanciamento social revela quão cruciais são o investimento e a efetivação das políticas públicas voltadas para a educação e que essas políticas devem estar alinhas às necessidades reais da população a ser atendida.

\section{Considerações finais}

A pandemia trouxe ao mundo a necessidade de identificação e reflexão de diversos aspectos da vida social e escolar. Além das estatísticas de número de infectados, número de óbitos, número de crianças sem escolas etc., a materialização dos inúmeros problemas e falhas do sistema escolar parece nos saltar aos olhos.

É impossível abranger todos os desafios que a educação escolar enfrenta diante da atual conjuntura; o presente artigo buscou apenas apontar reflexões e problematizar questões, algumas já não consideradas tão recentes, a fim de contribuir para o fortalecimento de um importante e fundamental o espaço público: a escola pública brasileira. 


\section{Educação em contexto de pandemia: breves reflexões}

Entendemos, assim como Neta, Nascimento e Falcão (2020), que com o isolamento social e o avanço do discurso de inovações tecnológicas como panaceia da educação (GATTI, 2020; SANTOS, C., 2020), o caráter democrático e universal da escola tem sido ameaçado pelas limitações do ensino remoto e tal situação encontra nas desigualdades sociais um dos maiores empecilhos a sua realização (NETA; NASCIMENTO; FALCÃO, 2020). Ainda, é necessário lembrar que o vírus "atinge a todos, porém ele não é tão democrático, a letalidade atinge os idosos, indivíduos com problemas associados e os socialmente vulneráveis" (SILVA; BINS; ROZEK, 2021, p. 130).

Os impactos causados por essas desigualdades ficaram evidentes em artigos apresentados neste texto e nos advertem que pequenas medidas, apenas, não resolvem problemas estruturais de nossa educação. Provavelmente, mais do que nunca, os educadores perceberam a premência de maiores e constantes investimentos em todos os setores da educação pública.

Gatti (2020) nos provoca com questões que nos parecem extremamente relevantes para o contexto atual e futuro: as situações vividas na pandemia provocarão, de fato, alterações substantivas quer do ponto de vista econômico, quer do cultural ou do social? Essa experiência possibilitará ultrapassar a visão atual de uma educação dentro de um modelo com visões apenas imediatistas e competitivas? Essas e outras perguntas nos instigam a entender a educação brasileira no contexto da dinâmica da sociedade brasileira, sem a desconsideração de suas características cotidianas mais íntimas.

\section{Referências}

ARAUJO E OLIVEIRA, João Batista. GOMES, Matheus. BARCELLOS, Thais. A Covid-19 e a volta às aulas: ouvindo as evidências. Ensaio: avaliação de políticas públicas em Educação. [online]. 2020, vol.28, n.108, pp.555-578. Disponível em: https://doi.org/10.1590/s0104-40362020002802885.

ARRUDA, E. P. Educação remota emergencial: elementos para políticas públicas na educação brasileira em tempos de Covid-19. Em rede. Revista de educação a distância, 7(1), 2020, 257-275. Disponível em: https://www.aunirede.org.br/revista/index.php/emrede/article/view/621

AVELINO, Wagner Feitosa, MENDES, Jessica Guimarães. A realidade da educação brasileira a partir da COVID-19. BOCA. Boletim de conjuntura. v. 2, n. 5 (2020). Disponível em https://revista.ufrr.br/boca/article/view/AvelinoMendes. Acesso em maio de 2021.

BERTUCCI-MARTINS, Liane Mara. Conselhos ao povo: educação contra a influenza de 1918. Cadernos CEDES, Campinas, v. 23, n.59, p. 103-117, abr., 2003. 35p. Disponível em: https://www.scielo.br/pdf/ccedes/v23n59/a08v23n59.pdf. 
BRASIL. CNE. MEC. Diretrizes para escolas durante a Pandemia. Disponível em: $<$ http://portal.mec.gov.br/component/content/index.php?option=com_content\&view=article\&id=89 051:cne-aprova-diretrizes-para-escolas-durante-a-pandemia> Acesso em: 13 mar. 2021

CARVALHO, José Sérgio Fonseca de I. Um Sentido para a Experiência Escolar em Tempos de Pandemia. Educação \& Realidade, Porto Alegre, v. 45, n. 4, e109144, 2020. Disponível em: http://dx.doi.org/10.1590/2175-6236109144

COUTO, Edvaldo Souza; COUTO, Edilece Souza; CRUZ, Ingrid de Magalhães Porto. \#FIQUEEMCASA: Educação na pandemia da COVID-19. Interfaces Científicas, Aracaju, v. 8, n. 3, p. 200-217, 2020. Disponível em: https://periodicos.set.edu.br/educacao/article/view/8777/3998

FERREIRA, Gesilaine Mucio; JANUÁRIO, Erika Ramos; MOREIRA, Jani Alves da Silva. Políticas para a educação especial inclusiva no Paraná e a COVID-19: ensino remoto emergencial. Revista Teias. v. 22., $\mathrm{n}^{\circ}$ 65, abr./jun. 2021. Disponível em: https://www.epublicacoes.uerj.br/index.php/revistateias/article/view/55782.

GATTI, Bernadete A. Possível reconfiguração dos modelos educacionais pós-pandemia. Estudos Avançados, São Paulo, v. 34, n. 100, p. 29-41, dez. 2020. Disponível em:http://www.scielo.br/scielo.php?script=sci arttext\&pid=S0103$\underline{40142020000300029 \& \operatorname{lng}=e n \& n r m=i s o}$.

GRISOTTI, M. Doenças infecciosas emergentes e a emergência das doenças: uma revisão conceitual e novas questões. Ciência \& Saúde Coletiva, Rio de Janeiro, v. 15, supl. 1, p. 1095 1104, Jun, 2010. Disponível em: https://www.scielo.br/scielo.php?pid=S1413$81232010000700017 \&$ script=sci_abstract\&tlng=pt.

GUIZZO, Bianca Salazar; MARCELLO, Fabiana de Amorim; MULLER, Fernanda. A reinvenção do cotidiano em tempos de pandemia. Educação e Pesquisa, São Paulo, v. 46, e238077, 2020. Disponível em:http://www.scielo.br/scielo.php?script=sci_arttext\&pid=S151797022020000100402\&lng=en\&nrm=iso.

KIND, L. CORDEIRO, R. Narrativas sobre a morte: A gripe espanhola e a COVID-19 no Brasil. Psicologia \& Sociedade, Belo Horizonte, v. 32, n., p., Set., 2020. Disponível em: https://www.scielo.br/scielo.php?script=sci_arttext\&pid=S0102-71822020000100403.

MONTEIRO, S. S. (RE)Inventar educação escolar no Brasil em tempos da COVID-19. Revista Augustus, Rio de Janeiro, v. 25, n. 51, p. 237-254, jul./out., 2020. Disponível em: https://revistas.unisuam.edu.br/index.php/revistaaugustus/article/view/552

NETA, Adelaide de Sousa Oliveira; NASCIMENTO, Romária de Menezes do; FALCÃO, Giovana Maria Belém. A educação dos estudantes com deficiência em tempos de pandemia de covid-19: a invisibilidade dos invisíveis. Interacções, $\mathrm{n}^{\circ}$. 54, pp. 25-48, 2020. Disponível em: https://revistas.rcaap.pt/interaccoes/article/view/21070

NETO, Mercedes; GOMES, Tatiana de Oliveira; PORTO, Fernando Rocha; RAFAEL, Ricardo de Mattos Russo; FONSECA, Mary Hellem Silva; NASCIMENTO, Julia Fake news no cenário da pandemia de Covid-19. Cogitare enfermagem. [Internet]. 2020; 25. Disponível em: http://dx.doi.org/10.5380/ce.v25i0.72627. 
NOZU, Washington Cesar Shoiti; KASSAR, Mônica de Carvalho Magalhães. Escolarização de crianças e adolescentes pantaneiros em tempos de COVID-19. Práxis Educativa (Impresso), v. 15, p. 1-21, 2020. Disponível em

https://revistas2.uepg.br/index.php/praxiseducativa/article/view/16193. Acesso em maio de 2021.

OZÓRIO, Francisca Janaina Dantas Galvão et al. Políticas Públicas para o Atendimento Educacional Especializado em Fortaleza durante a pandemia. Revista Práticas Educativas, Memórias e Oralidades, Fortaleza, v. 3, n. 1, p. 1-16, 2021. Disponível em:https://revistas.uece.br/index.php/revpemo/article/view/3864

Problema sem fim: internet banda larga fica mais de cinco horas interrompida. Diário Corumbaense, Corumbá, 05 de Mar. de 2021. Disponível em:

<https://diarionline.com.br/?s=noticia\&id=123151 > Acesso em: 20 de Mar. 2021.

SARAIVA, Karla; TRAVERSINI, Clarive e LOCKMANN; Kamila. A educação em tempos de COVID-19: ensino remoto e exaustão docente. Práxis Educativa, Ponta Grossa, v. 15, e2016289, p. 1-24, 2020 Disponível em: https://www.revistas2.uepg.br/index.php/praxiseducativa. SANTOS, Boaventura de Souza. A cruel pedagogia do vírus. Coimbra: Edições Almeida, S.A, 2020.

SANTOS, Claitonei de Siqueira. Educação Escolar no contexto de pandemia: Algumas reflexões. Gestão \& Tecnologia, v. 1, n. 30, p. 44-47, Jan./Jun., 2020. Disponível em: http://faculdadedelta.edu.br/revistas3/index.php/gt/article/view/52.

SILVA, K. W. da, BINS, K. L. G., \& ROZEK, M. (2020). A Educação Especial e a Covid-19: aprendizagens em tempos de isolamento social. Educação, 10(1), 124-136. Disponível em:Https://Doi.Org/10.17564/2316-3828.2020v10n1p124-136

SORJ, Bernardo; LISSOVSKY, Mauricio. Internet nas escolas públicas: políticas além da política. Working Paper $n^{\circ}$ 6, Centro Edelstein de Pesquisas Sociais. Março 2011. Disponível em: http://www.centroedelstein.org.br/PDF/WorkingPapers/Internet_Educacao_marco_2011.pdf. Acesso em maio, 2021.

VEIGA-NETO, Alfredo. Mais uma Lição: sindemia covídica e educação. I Educação \& Realidade, Porto Alegre, v. 45, n. 4, e109337, 2020. Disponível em: http://dx.doi.org/10.1590/21756236109337 